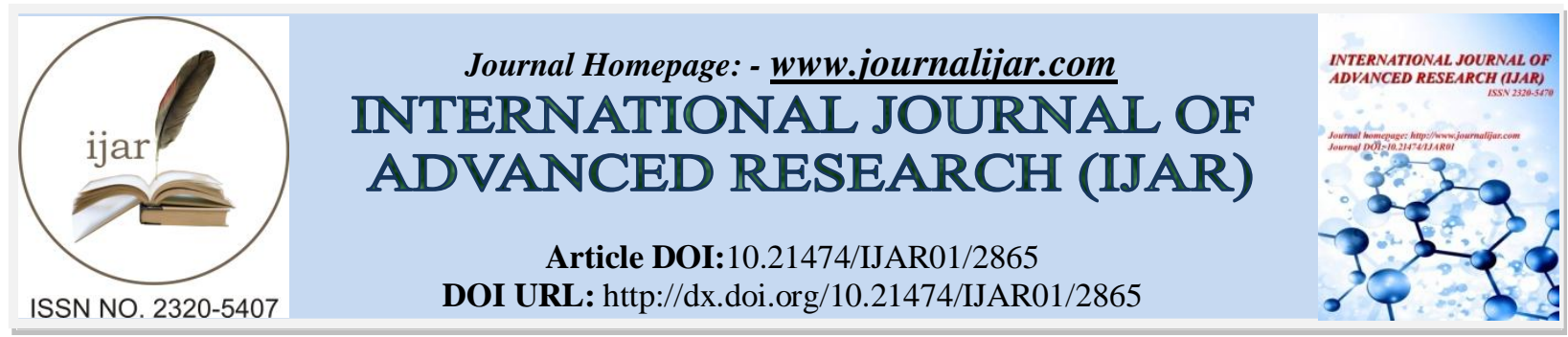

RESEARCH ARTICLE

\title{
EXPRESSION OF CD200 IN CD5 POSITIVE B-CELL LYMPHOPROLIFERATIVE DISORDER (B-CLL AND MCL) AND ITS ROLE IN THE DISCRIMINATION BETWEEN THESE DISORDERS.
}

\section{Dr. Hind shaker al-mamoori.}

\section{Manuscript Info}

Manuscript History

Received: 21 November 2016

Final Accepted: 21 December 2016

Published: January 2017

Key words:-

CD 200, B-CLL, MCL, CD5 POSITIVE LYMPHOPROLIFRATIVE DIEASES.

\section{Abstract}

Chronic B-cell lymphoproliferative disorders (B-CLPD) are a group of clonal diseases characterized by proliferations of mature $\mathrm{B}$ lymphocytes in the bone marrow (BM), peripheral blood, and lymphoid tissues.

Mature B-cell lymphoproliferative disorders is divided by CD5 expression into two groups:

1. CD5 (positive) diseases including B cell chronic lymphocytic leukemia (B-CLL) and mantle cell lymphoma (MCL).

2. CD5 (negative) diseases and including all the other forms of BCLPD.

Chronic lymphocytic leukemia (B-CLL) and mantle cell lymphoma (MCL) have many features in common and their differential diagnosis may be arduous, particularly when a leukemic phaseof lymphoma is the only presentation. immunophenotypic panels are often useful, with CD23 being the most validin B-CLL and in MCL suspected cases should be confirmed by immunohistochemically cyclin D1 detection but sometimeindefinite or some time negative repercussion may occur and other immunological markers and advanced cytogenetics or molecular techniques are bona fide but they add extra cost and not widely available. So we study the expression of CD 200 which is a membrane gpof the immunoglobulin superfamily in CD 5 positive mature B-cell lymphoproliferative disorders to help in differentiation.

Aim of the study: -

1. To detectthe immunohistochemically expression of CD200 in CD5 +ve Mature B-cell lymphoproliferative disorders.

2. Evaluation of the value of CD200 in diagnosis and differentiating between B cell chronic lymphocytic leukemia (B-CLL) and mantle cell lymphoma (MCL).

Patients, materials and methods: -

This cross sectional study included 49 adult patientsand newly diagnosed by morphology and flowcytometric immunophenotyping as B-CLL for score 4-5 and MCL with score <4conducted from February 2015 to September 2016 from many centers, Baghdad teaching hospitals and private clinic.

From each patient, left over samples were used. 
Bone marrow trephine biopsy sections were stained with hematoxylin and eosin for histopathological assessmentfurther detection for the expression of cyclin D1 and CD200were performed by immunohistochemistry technique.

Results: - The patients were 36 males and 13 females newly diagnosed as CD5 positive mature B-cell lymphoproliferative disorder, 39 patients were presented with B-chronic lymphocytic leukemia and 10 were mantle cell lymphomadiagnosed by morphological assessment and flowcytometric immunophenotyping as B-CLL with score 4-5 and MCL with score <4, MCL diagnosis proved by immunohistochemically expression of cyclin D1.

The result showed thatCD200 was expressed in 37 (94.9\%) out of 39 chronic lymphocytic leukemia patientswhile mantle cell lymphoma cases were all negative for CD200 expression.

Highly significant association between CD200 expression and B-CLL, $\mathrm{p}$ valuewas $<0.001$ and negative in 2 cases $(5.1 \%)$ shown to have an advanced disease.

Conclusions: - CD200 is highly expressed in B-CLL and it has a discriminative role in mature $\mathrm{CD} 5$ positive $\mathrm{B}$-cell lymphoproliferative disorders (B-CLL and MCL). The only CD 200 negative CLL cases might related to the advanced stage of disease.

Copy Right, IJAR, 2016,. All rights reserved.

\section{Introduction: -}

Chronic mature B-cell lymphoproliferative disorders (B-CLPD) are a group of clonal diseases characterized by proliferation of mature looking B lymphocytes in the bone marrow, peripheral blood, and lymphoid tissues. BCLPD diagnosis can be made by morphological, and immunophenotyping that help in differentiation between different types of mature B-cell lymph proliferative disorders (B-CLPD) and this supported by cytogenetic parameters, as is described in the World Health Organization classification (WHO). (1)

Immunohistochemically immunophenotypic analysis is particularly helpful in establishing the diagnosis because there is significant overlap in clinical and morphologic features between these diseases entities and as the B-CLL and mantle cell lymphoma have many features in common and they may give equivocal or negative result for the specific markers used for differentiation so a more advanced cytogenetic or molecular tests are required but they add extra cost and might not be available. (2)

Such difficult cases of B-CLPDs can be further sub classified according to the expression of CD5.Patients with CD5 negative B-CLPD usually present as the leukemic phase of lymphoma such as marginal zone lymphoma (MZL), lymphoplasmacytic lymphoma (LPL), follicular cell lymphoma (FCL), or hairy cell leukemia (HCL); While patients with CD5 positive B-CLPD can be either B-CLL or mantle cell lymphoma in which differentiations between them may be so difficult as they do not have the characteristic immunophenotypic score of CLL or mantle cell lymphoma (MCL) (i.e. CD5+B-CLPD).(3), (4), (5).

CD200 is a membrane gp MRC (OX-2).It is a member of the immunoglobulin superfamily which is encoded by a gene at chromosome 3q12; This transmembrane protein is expressed on different cell types, and it is expressed by endothelial cells and neurons and by Blymphocyte and a subset of T lymphocyte; It plays an important role in the regulation of anti-tumor immunity (5), and overexpression of $\mathrm{CD} 200$ has been reported in a number of malignancies, including CLL, because of its differential expression in B-CLL and mantle cell lymphoma (MCL), we evaluate this expression differences on these two disorders.

\section{Materials and Methods: -}

This cross sectional study was conducted on 49 adult patients newly diagnosed mature CD5 positive BCLPD, 39 patients were presented with chronic lymphocytic leukemia diagnosis depend on the WHO classification of mature B-cellNeoplasmswith score 4-5 and 10 were mantle cell lymphoma score $<4$ (1). The diagnosis of which was 
confirmed by the demonstration of cyclin D1 expression by immunohistochemistry, the cases were randomly selected for the age and sex.

\section{The samples for each patient were subjected to the following procedures: -}

1. Samples were leftover.

2. Bone marrow biopsy was fixed with formalin solution and stained byhematoxylin and eosin for histopathological examination.

3. Immunohistochemistry technique on bone marrow biopsy used to detectCD200 to assess its differential expression on B-CLL and MCL.

\section{Procedures: -}

Processing of B.M biopsy and immunohistochemistry: -

Sections slides were stained with hematoxylin and eosin and sections were fixed onpositively charged slides for immunohistochemically tests forCD200 each section was with 4-micronthickness, procedure of immunohistochemistry used in this study was adopted by abcam ${ }^{\circledR}$

All steps are performed at room temperature.

\section{Staining protocol: -}

1. Deparaffinize and rehydrate formalin fixed paraffin-embedded tissue section.

2. Add enough drops of hydrogen peroxide block to cover the section. Incubate for 10 minutes. Wash 2 times in buffer.

3. Apply protein block an incubate for 10 minutes at room temperature to block nonspecific background staining. Wash 1 time in buffer.

4. Apply primary antibody and incubate.

5. Wash 3 times in buffer solution.

6. pour complement and incubate for ten minutes at room temperature. Wash 2 times in buffer solution.

7. Pour HRP conjugate and incubate for 15 minutes at RT

8. Rinse four times in buffer solution. Add $30 \mu \mathrm{l}$ (1drop) DAB chromogen to $1.5 \mathrm{ml}$ of DAB substrate, mix by swirling and apply to the tissue. Incubate for 10 minutes. Rinse 4 times in buffer.

9. Apply counter stain

10. Dehydrate and coverslip.

The slides were examined by light microscope and scanned on low and high powers (10x, 40x). Assessment of immunohistochemically staining: -

The scoring systems for CD200 were scored positive if $20 \%$ or more of the cells within an aggregate showed brown cellular membrane and/or cytoplasmic staining pattern. (6)

\section{Statistics: -}

A non-parametric two-way contingency table test (Fisher exact test) was employed, using Prism 7 for Mac OS X software, ver. 7.0a (Graph Pad Software, San Diego, California). The validity of CD200 in discrimination of B-CLL than MCL was calculated using sensitivity, specificity, positive and negative predictive values.

\section{Result: -}

Thirty-ninepatients with B-CLL and ten with MCL were enrolled in this study, patients were randomly selected for the age and sex as shown in the table 1. The male to female ratio in B-CLL cases were 2.5:1 and in MCL were 4:1.

Table 1: -age and sex distribution.

\begin{tabular}{|c|c|c|c|c|}
\hline & \multicolumn{2}{|l|}{ Study groups } & \multirow[t]{2}{*}{ P value } \\
\hline & & CLL & MCL & \\
\hline \multicolumn{2}{|c|}{$\begin{array}{l}\text { Age (years) } \\
\text { Mean } \pm \text { SD } \\
\text { (Minimum-Maximum) }\end{array}$} & $\begin{array}{l}60.08 \pm 11.15 \\
(39-80)\end{array}$ & $\begin{array}{l}57.7 \pm 4.3 \\
(50-64)\end{array}$ & $\mathbf{0 . 7 8 4}^{\mathrm{NS}}$ \\
\hline \multirow[t]{2}{*}{ Sex } & Male (\%) & $28(71.8)$ & $8(80)$ & \multirow[t]{2}{*}{$0.467^{\mathrm{NS}}$} \\
\hline & Female $(\%)$ & $11(28.2)$ & $2(20)$ & \\
\hline
\end{tabular}


Binet stages were available for B-CLL cases and were as shown in table 2

Table 2: - Binet staging system for B-CLL

\begin{tabular}{|l|l|l|}
\hline Binet stage & & \\
\hline A & 30 & $76.9 \%$ \\
\hline B & 7 & $17.9 \%$ \\
\hline C & 2 & $5.1 \%$ \\
\hline Peripheral blood lymphocytes $\left(1^{9}\right.$ per liter $)$ & 22.1 & $15-35$ \\
\hline Hb (g/100 ml) & 13 & $10.5-13.6$ \\
\hline Platelets $\left(10^{9}\right.$ per liter) & 145 & $95-190$ \\
\hline
\end{tabular}

CD200 was expressed by $94.9 \%$ of our CLL cases as shown in figure 1 compared with 0\% of MCL cases as shown in figure 2. The cut-off value of $\mathrm{CD} 200$ percent expression on malignant clone cells in both groups was $20 \%$, it had $99.37 \%$ sensitivity, $100 \%$ specificity, $100 \%$ positive predictive value, and $83.33 \%$ negative predictive value as shown in the table 3.
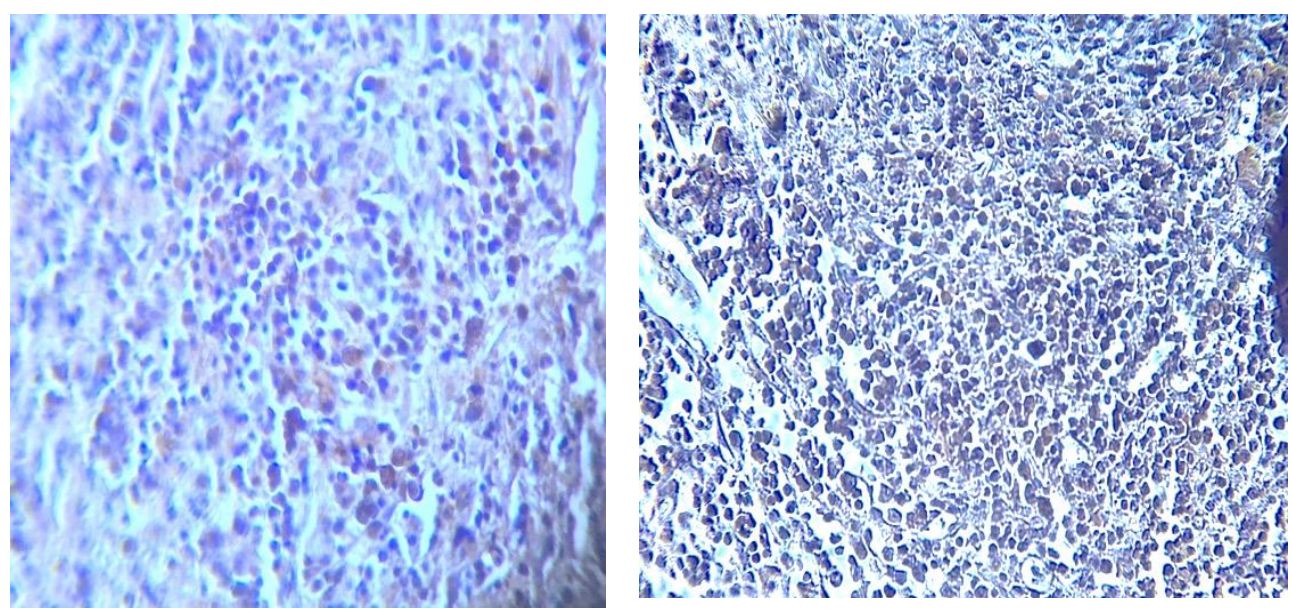

Figure 1: -Cytoplasmic positivity for CD200 in B-CLL.

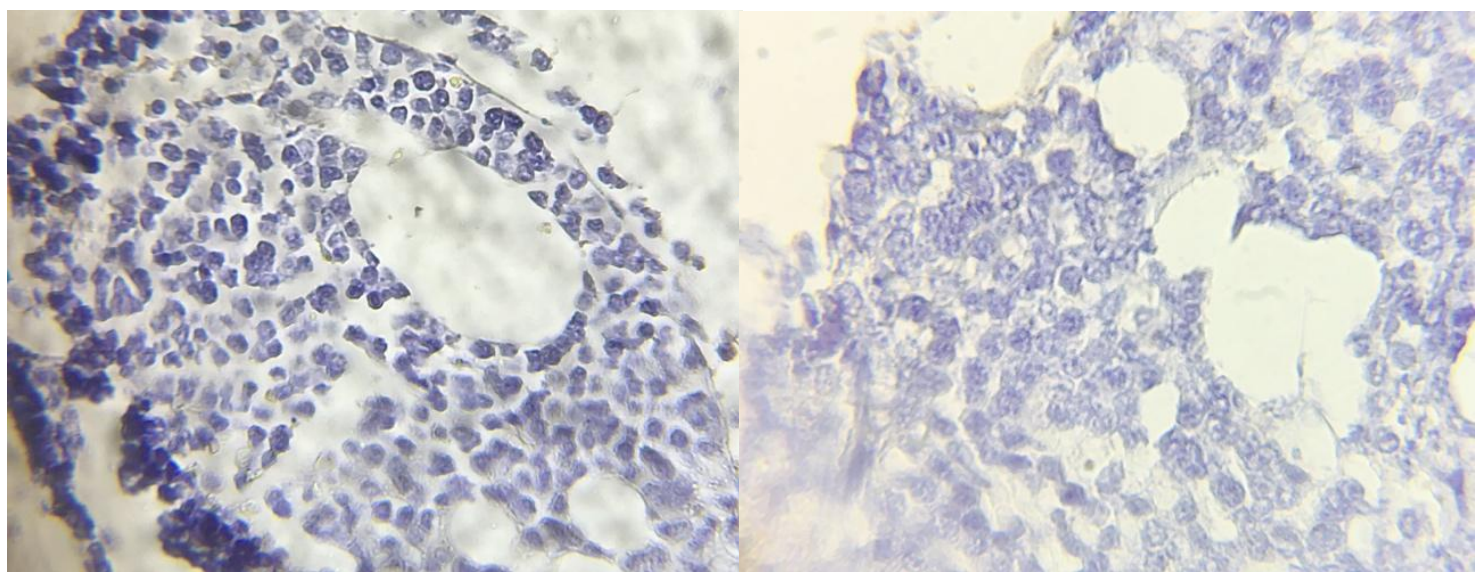

Figure 2: -cytoplasmic negativity for CD200 in MCL 
Table 3: -The CD 200 expression on the two studied groups.

\begin{tabular}{|c|c|c|c|c|c|c|c|c|}
\hline & \multicolumn{2}{|c|}{ Study groups } & \multirow[t]{2}{*}{ P value } & \multirow{2}{*}{$\begin{array}{l}\text { Sensitivity } \\
\text { (CI) }\end{array}$} & \multirow{2}{*}{$\begin{array}{l}\text { Specificity } \\
\text { (CI) }\end{array}$} & \multirow[t]{2}{*}{ PPV } & \multirow[t]{2}{*}{ NPV } & \multirow{2}{*}{$\begin{array}{l}\text { Kappa } \\
\text { index }\end{array}$} \\
\hline & $\begin{array}{l}\text { CLL } \\
\text { (4-5) }\end{array}$ & $\begin{array}{l}\text { MCL } \\
(<4)\end{array}$ & & & & & & \\
\hline $\begin{array}{l}\text { CD200 } \\
\text { positive } \\
(\%)\end{array}$ & $\begin{array}{l}37 \\
(94.9)\end{array}$ & 0 (0\%) & $<0.001 * *$ & $\begin{array}{ll}94.87 & \\
82.68 & \text { to } \\
99.37 & \end{array}$ & $\begin{array}{l}100 \\
69.15 \\
100.00\end{array}$ & 100 & $\begin{array}{l}83.33 \\
56.45 \text { to } \\
95.07\end{array}$ & 0.883 \\
\hline $\begin{array}{l}\text { CD200 } \\
\text { negative } \\
(\%)\end{array}$ & $2(5.10)$ & $10(100)$ & & & & & & \\
\hline Total & 39 & 10 & & & & & & \\
\hline
\end{tabular}

\section{Discussion: -}

Chronic mature B-cell lymphoproliferative disorders (B-CLPD) are a group of malignant diseasesmarked by accumulation of mature looking B lymphocytes in the bone marrow, peripheral blood, and lymphoid tissues. B-CLL and MCL both are CD5+ve mature B lymphocyte neoplasms that show differences in the outcomes, modality of treatment and outcomes; B-CLL tends to follow an indolent course, having median survival ranging from 8 to 12 years depending on gene mutational status of immunoglobulin. While in MCL the disease shows a more clinical aggression and treatment-resistant over the time. with a mediansurvival of 3 to 7 years. (7). Thus differentiation of these disorders has vital role prognostically and therapeutically (8). The conjunction of clinical features, morphology and immunological features can lead to an accurate diagnosis in the majority of the cases of B cell chronic lymphoproliferative disorders; but the diagnosis remains uncertain in a small percentage of cases. The characteristic immunophenotypic features of CLL are aberrant expression of CD5, together with CD23 expression and the negativity of CD79b and FMC7 (9).

This is in contrast to MCL, who also express CD5 and lack CD23 expression and strongly express FMC7. The most important helpful markers in their differentiation are CD23 and FMC7. MCL is CD23-ve and FMC7+ve, while CLL usually have the opposite. however aberrant phenotypes may occur as reported by previous studies... whose found that CD23 positivity in CLL ranged from 86.6 to $100 \%$ of caseswhile CD23 expression was found in about half of MCLcases and FMC7 positivity of $0-12 \%$ inCLL cases $(10,11)$ and $90-100 \%$ in MCL $(10,12)$ so in these cases flow cytometric discrimination of CLL from MCL can be arduous.

In this study, we scrutinized the expression of CD200 on the clonal cells of patients with B-CLL and MCL.CD200 was expressed in $94.9 \%$ CLL cases compared with $0 \%$ in MCL cases.And the results showed that there were highly significant differences between these two disorders. CD200 expression in which $\mathrm{P}$ was $<0.001$, the results also showed that CD200 expression was negative in only two cases of B-CLL who were known to have an advanced diseases shown in table 2 according to Binet staging (stage C). CD200 positivity showed a positivepredictive value of $100 \%$, a negative predictive value of $83.33 \%$, a sensitivity of $94.87 \%$, and a specificity of $100 \%$.

The results of this studyin agree with previous studies which confirm the uniform expression CD200 on B-CLL cases and the only negative B-CLL were stage C so there may be a relation between the CD200 expression and the prognosis this need an expanded study. this agree with Alapat et al. (13) and Dahlia A. El-Sewefy et al. (14)

So the inclusion of CD200 in routine panels can be very helpful in distinguishing between thesetwo disease, specially, in patients with inconclusive phenotypes.

\section{Conclusion: -}

CD200 is highly expressed in B-CLL and it has a discriminative role in mature CD5+ve B-CLPD (B-CLL and MCL). The only CD 200 negative CLL case might related to the advanced stage of disease, so more expanded study required to correlate the CD200 expression and the prognosis of the disease. 


\section{References: -}

1. Swerdlow SH, Campo E, Harris NL, Jaffe ES, Pileri SA, Stein H, et al. WHO classification of tumours of haematopoietic and lymphoid tissues. Lyon: IARC press; 2008.

2. Craig FE, Foon KA. Flow cytometric immunophenotyping for hematologic neoplasms. Blood 2008; 111:39413967.

3. Barna G, Reiniger L, Tátrai P, Kopper L, Matolcsy A. The cut-off levels of CD23 expression in the differential diagnosis of MCL and CLL. Hematol Oncol 2008; 26:167-170.

4. Ho AK, Hill S, Preobrazhensky SN, Miller ME, Chen Z, Bahler DW. Small B-cell neoplasms with typical mantle cell lymphoma immunophenotypes often include chronic lymphocytic leukemias. Am J Clin Pathol 2009; 131:27-32.

5. Hanson CA, Morice WG. The clinical and laboratory approach to the CD5/CD10 negative B-cell chronic lymphoproliferative leukemias. Am J Hematol. 2008;83(5):347-348.

6. Palumbo GA, Fargione G, Parrinello N, Cardillo K, Chiarenza A, Berretta S, et al. CD200 as a tool for differential diagnosis between B-cell chroniclymphocytic leukemia and mantle cell lymphoma. Haematologica 2008; 93:33.

7. Ghielmini M, Zucca E. How I treat mantle cell lymphoma. Blood 2009;114:1469-1476.

8. Zhao XF. Pitfalls in diagnostic hematopathology: part I. Int J Clin Exp Pathol 2009; 2:11-20.

9. Jaffe ES, Harris NL, Stein H, Vardiman JW, editors. World Health Organization classification of tumours: pathology and genetics of tumours of haematopoietic and lymphoid tissues. Lyon, France: IARC Press; 2001.

10. Ahmad E, Garcia D, Davis BH. Clinical utility of CD23 and FMC7 antigen coexistent expression in B-cell lymphoproliferative disordersubclassification. Cytometry 2002; 50:1-7.

11. Monaghan SA, Peterson LC, James C, Marszalek L, Khoong A, Bachta DJ. Pan B-cell markers are not redundant in analysis of chronic lymphocytic leukemia (CLL). Cytometry B Clin Cytom 2003; 56:30-42.

12. Garcia DP, Rooney MT, Ahmad E, Davis BH. Diagnostic usefulness of CD23 and FMC-7 antigen expression patterns in B-cell lymphoma classification. Am J Clin Pathol 2001; 115:258-265.

13. Alapat D, Coviello-Malle J, Owens R, Qu P, Barlogie B, Shaughnessy JD, et al. Diagnostic usefulness and prognostic impact of CD200 expression in lymphoid malignancies and plasma cell myeloma. Am J Clin Pathol 2012; 137:93-100.

14. Dahlia A. El-Sewefy, Dina A. Khattab, Mohamed T.H. Sallam, et al Flow cytometric evaluation of CD200 as a tool for differentiation between chronic lymphocyticleukemia and mantle cell lymphoma. ehj.eg2014 39:42-46. 